\title{
An iron stress operon involved in photosynthetic electron transport in the marine cyanobacterium Synechococcus sp. PCC 7002
}

\author{
Karin LeONHardT and NeIl A. Straus* \\ Department of Botany, University of Toronto, Toronto, Ontario, Canada M5S $3 B 2$
}

(Received 19 March 1992; revised 22 April 1992; accepted 27 April 1992)

\begin{abstract}
The iron-stress-induced genes isi $A$ and $i s i B$ have been cloned and sequenced from the marine unicellular cyanobacterium Synechococcus sp. PCC 7002. These genes code for a photosystem II chlorophyll-binding protein and flavodoxin respectively. The genes form a dicistronic operon that is transcriptionally activated under ironstress conditions to produce an abundant monocistronic message containing isi $A$ and a much less abundant dicistronic message that also contains $i s i B$. The arrangement of these genes, their transcriptional control and the relative abundance of the monocistronic and dicistronic messages produced under iron stress parallels the pattern shown by the freshwater cyanobacterium Synechococcus sp. PCC 7942. The genes for the corresponding proteins found under iron-replete conditions, CP-43 and ferredoxin, have also been cloned and sequenced. Northern blot analysis indicates that both of these genes are constitutively expressed under both iron-stress and iron-replete conditions.
\end{abstract}

\section{Introduction}

Although iron is normally abundant in aqueous, oxic ecosystems, its low solubility above neutral $\mathrm{pH}$ may limit its biological availability. This is a crucial problem to aquatic organisms since iron is an essential component of cytochromes, and of ferredoxins and other iron-sulphur proteins. It is particularly critical for the growth of microbial populations because each round of cell division necessitates a doubling of the iron-containing molecules. When faced with conditions of iron deprivation, cyanobacteria pursue three strategies for survival. First, like other bacteria, they improve their iron acquisition capabilities by producing siderophores to scavenge any available iron from the environment (Crosa, 1989; Bagg \& Neilands, 1987; Boyer et al., 1987). Second, they decrease the amount of photosynthetic and respiratory redox proteins that contain iron (Pardo et al., 1990; Sandmann, 1985). Third, they replace ironcontaining proteins with non-iron-containing functional equivalents; for example, $\mathrm{Fe}-\mathrm{S}$-containing ferredoxin is replaced with flavodoxin as the terminal electron acceptor of photosynthesis (Hutber et al., 1977).

\footnotetext{
* Author for correspondence. Tel. (416) 978 3532; fax (416) 978 5878; Email: strausna@gpu.utcs.utoronto.ca.

The nucleotide sequence data reported in this paper have been submitted to GenBank and have been assigned the accession numbers M88251 and M88253
}

In the freshwater cyanobacterium Synechococcus sp. PCC 7942, the gene for flavodoxin, isiB, is the second open reading frame of a dicistronic message whose appearance is tightly regulated by iron concentration (Laudenbach et al., 1988). The first open reading frame of this message contains a gene, isiA, that is very similar to $p s b C$ (Laudenbach \& Straus, 1988). To investigate whether this iron stress response is a more general feature of cyanobacteria, we have studied the organization and transcriptional regulation of these genes in the marine cyanobacterium Synechococcus sp. PCC 7002. In this paper, we report on the cloning and sequencing of $i s i A$, isiB, psbC and pet $F$ from Synechococcus sp. PCC 7002. Northern blot analysis of RNA from cells in different iron regimes shows that isi $A$ and $i s i B$ form a dicistronic operon that is transcriptionally regulated to express under iron stress in the same way as in Synechococcus sp. PCC 7942. We also show that petF and $p s b C$ are constitutively expressed under all iron regimes tested.

\section{Methods}

Materials. All chemicals were reagent grade. Restriction endonucleases were obtained from Pharmacia, Bethesda Research Laboratories and New England Biolabs. Alkaline phosphatase was obtained from Boehringer Mannheim; DNA polymerase I Klenow fragment from Pharmacia; T4 polynucleotide kinase and AMV reverse transcriptase from New England Biolabs; and T4 DNA ligase from Bethesda Research Laboratories. $\left[\alpha^{32} \mathrm{P}\right] \mathrm{dCTP}\left(3000 \mathrm{Ci} \mathrm{mmol}{ }^{-1}\right)$ was 
obtained from ICN, and $\left[\gamma^{32} \mathrm{P}\right] \mathrm{ATP}\left(5000 \mathrm{Ci} \mathrm{mmol}{ }^{-1}\right)$ and $\left[{ }^{35} \mathrm{~S}\right] \mathrm{dATP}$ $\left(1000 \mathrm{Ci} \mathrm{mmol}^{-1}\right)$ were obtained from Amersham $(1 \mathrm{Ci}=37 \mathrm{GBq})$. 'Gene Clean' glass milk was obtained from Bio/Can Scientific.

Culture conditions. Synechococcus sp. PCC 7002 (Agmenellum quadruplicatum PR-6) was grown in A medium (Stevens \& Porter, 1980) at $29^{\circ} \mathrm{C}$ in liquid culture or on plates containing $1 \%(\mathrm{w} / \mathrm{v})$ agar (Difco). For growth under controlled iron conditions, citric acid was omitted and ferric ammonium citrate was replaced with the desired amount of ferric chloride. Normal iron conditions constitute $1.4 \times 10^{-5} \mathrm{M}-\mathrm{Fe}^{3+}$ while low-iron cultures were grown at $7.1 \times 10^{-7} \mathrm{M}-\mathrm{Fe}^{3+}$. All media were made in acid-washed glassware with deionized, ultrapure water from a Milli-Q Reagent Water System (Millipore Canada).

Library construction and screening. Genomic DNA of Synechococcus sp. PCC 7002 was isolated using a modification of the CTAB (cetyltrimethylammonium bromide) technique developed for chloroplast DNA (Milligan, 1989). The cell pellet was resuspended in $100 \mathrm{~mm}$-Tris, $20 \mathrm{~mm}$-EDTA, $3 \mathrm{mg}$ lysozyme $\mathrm{ml}^{-1}$ and incubated at $37^{\circ} \mathrm{C}$ for $1 \mathrm{~h}$ with intermittent shaking. Lysis was achieved by adding an equal volume of $100 \mathrm{~mm}$-Tris, $20 \mathrm{~mm}$-EDTA, $2.8 \mathrm{M}-\mathrm{NaCl}, 4 \%(\mathrm{w} / \mathrm{v})$ $\mathrm{CTAB}, 0.4 \%(\mathrm{v} / \mathrm{v})$ mercaptoethanol, and incubating at $55{ }^{\circ} \mathrm{C}$ for $45 \mathrm{~min}$. The DNA was spooled on a glass rod at each alcohol precipitation step.

Partial plasmid libraries were constructed using restriction-enzymecut genomic DNA separated by size on a low-melting-temperature agarose gel. Regions containing DNA of the appropriate insert size were cut out of the gel and the purified DNA was cloned. Transformations into Escherichia coli JM109 were carried out by the method of Hanahan (1985). The libraries were screened by using the original cloning enzyme to digest the DNA from pooled groups of 25 clones and performing Southern hybridization to identify clones of interest. Phage $\lambda N M 1149$ libraries were constructed as described by Pirrotta (1986) using the Packagene packaging system (Promega). Screening of $\lambda$ libraries in E. coli LE392 and C600hfl via plaque lifts, purification of $\lambda$ DNA incorporating a glycerol step gradient, and plasmid DNA isolation were carried out as described by Sambrook $e t$ al. (1989). Hybridization probes were respective genes cloned from Synechococcus sp. PCC 7942 (see Results).

RNA isolation and Northern blot analysis. Total RNA from exponentially growing cells was isolated as described by Golden $e t$ al. (1987). RNA was denatured with glyoxal and dimethyl sulphoxide, loaded onto a $1 \cdot 1 \%(\mathrm{w} / \mathrm{v})$ agarose gel and electrophoresed according to Sambrook et al. (1989). RNA was transferred to nylon membranes (Nytran; Schleicher and Schuell) using the Vacugene transfer system (Pharmacia) and a transfer solution of $7.5 \mathrm{~mm}-\mathrm{NaOH}$. Northern hybridization was carried out at $65^{\circ} \mathrm{C}$ as described by Sambrook et al. (1989).

Nucleotide sequencing, sequence analysis and primer extension analysis. Single-stranded M13mp18/19 DNA was isolated by the method of Dale et al. (1985) and sequenced using the commercial Sequenase kit (United States Biochemical). Oligonucleotide primers were prepared on a Cyclone DNA synthesizer (Biosearch). DNA sequence analyses, protein sequence alignments and protein similarity comparisons were performed using Microgenie version 6.0 (Beckman Instruments).

Primer extension was carried out using the method of Kjems \& Garrett (1988) developed for reverse transcriptase sequencing, omitting the dideoxynucleotides from the extension mixture.

\section{Results}

Cloning and sequence analysis of the isi operon

In order to see whether Synechococcus sp. PCC 7002 contains isiA and whether the arrangement of isiA and
isiB that was observed in PCC 7942 is conserved in Synechococcus sp. PCC 7002, both genes were cloned and sequenced for PCC 7002. The DNA fragment containing the flavodoxin gene of Synechococcus sp. PCC 7942 was used as a probe to identify a $0.8 \mathrm{~kb}$ SacI/HindIII fragment that contains the corresponding gene in Synechococcus sp. PCC 7002. This fragment was cloned into $\mathrm{M} 13 \mathrm{mp} 18$ and $\mathrm{mp} 19$ and completely sequenced. The sequence data indicated that the clone contained part of isiA and terminated just before the end of isiB. The $0.8 \mathrm{~kb}$ SacI/HindIII fragment was then used as a probe to clone the remainder of the gene for flavodoxin as a $1.1 \mathrm{~kb} \mathrm{SacI} / \mathrm{Cla \textrm {I }}$ fragment into pDPL13 (Gendel et al., 1983) for double-stranded sequencing. To clone the remainder of isiA, an EcoRI library in $\lambda \mathrm{NM} 1149$ was probed with a DNA fragment containing the isiA gene from Synechococcus sp. PCC 7942. The hybridizing $\lambda$ clone contained a $3.6 \mathrm{~kb} E c o$ RI fragment. Since repeated attempts to subclone the $3.6 \mathrm{~kb}$ fragment into pUC19 were unsuccessful, a $2.0 \mathrm{~kb} \mathrm{HindIII} / \mathrm{SacI}$ fragment was subcloned into M13mpl8 and mp19 and sequenced. Fig. 1 contains the map of the $i s i A B$ operon. To verify the continuity of the $2.0 \mathrm{~kb} H$ indIII/SacI fragment and the $0.8 \mathrm{~kb} \mathrm{SacI} /$ HindIII fragment, the $3.6 \mathrm{~kb}$ EcoRI fragment was isolated from a low-melting-temperature electrophoretic gel and further purified with 'Gene Clean' glass milk. Double-stranded sequencing across the SacI site indicated that these fragments were adjacent. Fig. 2 contains the nucleotide sequence for the isi $A B$ operon including surrounding regions.

The operon contains two open reading frames. The first open reading frame codes for a putative polypeptide containing 342 amino acids; this polypeptide shares a similarity of $75.4 \%$ with the putative isiA protein of Synechococcus sp. PCC 7942. The second open reading frame codes for a mature polypeptide with 169 amino acids (assuming proteolytic cleavage of the initial methionine residue; Drummond, 1985). This polypeptide shares a similarity of $69.0 \%$ with flavodoxin of Synechococcus sp. PCC 7942 and a similarity of $67 \%$ with that of Anabaena sp. PCC 7120 (Leonhardt \& Straus, 1989); the flavin-mononucleotide-binding regions (Smith et al., 1983; Laudenbach et al., 1988) are highly conserved in all three species.

Potential transcriptional termination structures are found within the sequence shown in Fig. 2. One occurs $55 \mathrm{bp}$ downstream of the isiA open reading frame with an 8-base inverted repeat structure, a loop of 6 bases and a thermal stability of $\Delta G=-9.6 \mathrm{kcal} \mathrm{mol}^{-1}(40.2 \mathrm{~kJ}$ $\mathrm{mol}^{-1}$ ). The stem structure is followed by a string of $6 \mathrm{~T}$ residues, as is common in rho-independent prokaryotic transcription terminators (Rosenberg \& Court, 1979). The second palindromic sequence, which is not followed by a string of Ts, occurs $19 \mathrm{bp}$ after the flavodoxin gene sequence. It consists of a 9-base stem and a loop of 


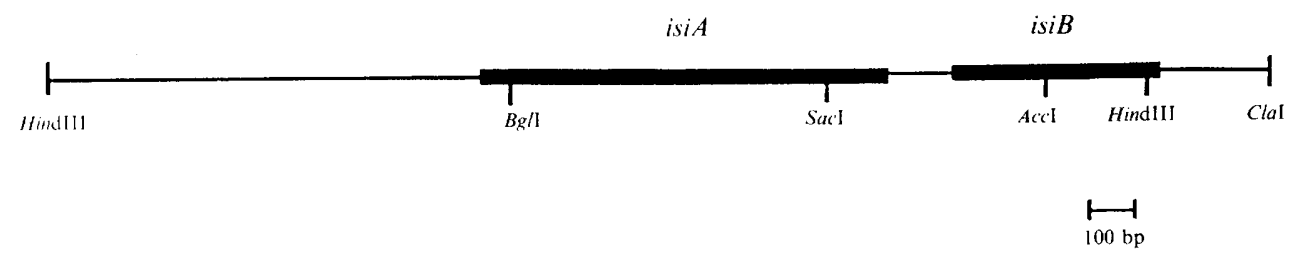

Fig. 1. Partial restriction map of the isiAB operon of Synechococcus sp. PCC 7002.

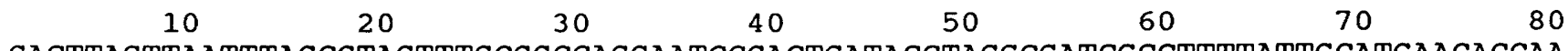
GACTTAGTTAATTTAGCGTAGTTTGCGGCCAGGAATCCGACTGATACCTAGGCGATCGCCTTTTATTGCATGAACACCAA

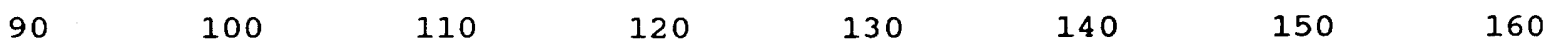
CTGATAATTAATAGTGATAAAACTTGTCTGAAATAATTATTGGGTTTCTTCATATCAAAACTGATTAGCAAAAAAGACGT
170
180
190
200
210
220
230
240

GATCGTTGCGGCGAGAAGTGGAGCGAGAAATTCGTAAAAACTCCTATTTTCTTTGCAGAGATAAGGTTTTTGGTCTCATG

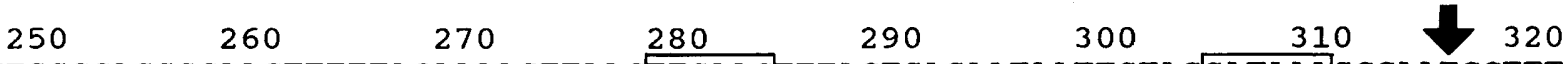
GAGTGATTGGCCAGGGCAACTTTTTACAAAAGTTAA

$\begin{array}{lllllll}330 & 340 & 350 & 360 & 370 & 380 & 390\end{array}$

ATTGCCAAATATATGCGATAAGTGATTAGCCTGATTAGTTTTAACGACCACTCTTTTTAAAATCACGATGCAAACCTACG

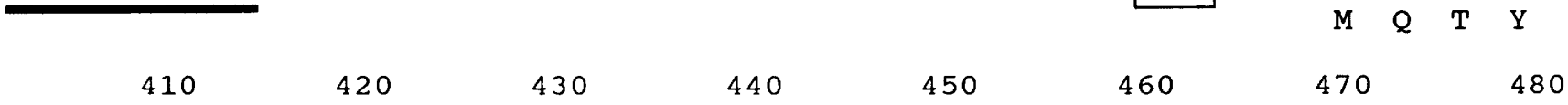
ATAATCCAGACGTTAAATACGAATGGTGGGCAGGCAATGCCCGGTTTGCTGACCTTTCCGGTCAGTTTATTGGTGCCCAC

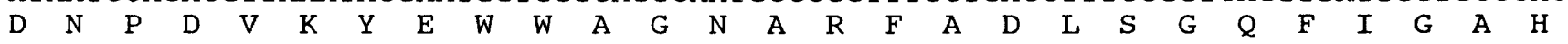

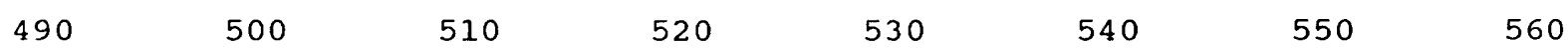
GTGGCCCATGCTGCCTTAATTGTTTTCTGGGCAGGGGCCTTCACGTTGTTCGAAATTTCTTACTTTGACCCGACCCTACC $\begin{array}{llllllllllllllllllllllllllll}V & A & H & A & A & \text { L } & \text { I } & \text { V } & \text { F } & \text { W } & \text { A } & \text { G } & \text { A } & \text { F } & \text { T } & \text { L } & \text { F } & \text { E } & \text { I } & \text { S } & \text { Y } & \text { F } & \text { D } & \text { P } & \text { T } & \text { L } & \text { P }\end{array}$

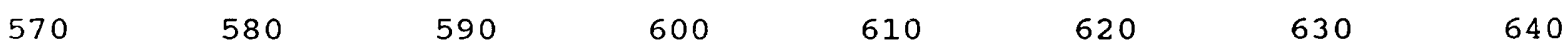
CATGGGCGAGCAAAATTTAATCCTCTTGCCCCATTTAGCCACCCTTGGCCTGGGCATCGAAGGAAACGGTGCGATCAATA $\begin{array}{lllllllllllllllllllllllllllll}M & G & E & Q & N & L & I & L & L & P & H & L & A & T & L & G & L & G & I & E & G & N & G & A & I & N\end{array}$ $\begin{array}{lllllll}650 & 660 & 670 & 680 & 690 & 700 & 710\end{array}$ CAGAGCCTTATTTTGTGATTGGTGCAATTCACCTAATTTCTTCAGCGGTACTGGCGGCAGGGGGATTGTTCCATGTGTTG $\begin{array}{llllllllllllllllllllllllllllllllll}T & E & P & Y & F & V & I & G & A & I & H & L & I & S & S & A & V & L & A & A & G & G & I & F & H & V & L\end{array}$ $\begin{array}{lllllll}730 & 740 & 750 & 760 & 770 & 780 & 790\end{array}$ CGTGGCCCCCAAGATCTCAAAACAGCCACCGGCCCAGCCCGTCGTTTCCATTTTGATTGGGAAGACCCGAAGCAATTGGG $\begin{array}{lllllllllllllllllllllllllll}R & G & P & Q & D & L & K & T & A & T & G & P & A & R & R & F & H & F & D & W & E & D & P & K & Q & L & G\end{array}$ $\begin{array}{lllllll}810 & 820 & 830 & 840 & 850 & 860 & 870\end{array}$ TTTAATTTTGGGCCATCACTTACTGTTGCTGGGACTGGGTGCTTTCTTGCTCGTAGCGAAAGCGATGTACTTTGGCGGTT $\begin{array}{lllllllllllllllllllllllllll}L & I & L & G & H & H & \text { L } & \text { L } & \text { L } & \text { L } & \text { G } & \text { L } & \text { G } & \text { A } & \text { F } & \text { L } & \text { L } & \text { V } & \text { A } & \text { K } & \text { A } & \text { M } & \text { Y } & \text { F } & \text { G } & G\end{array}$

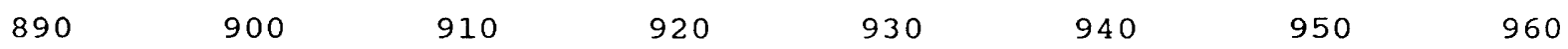
TGTACGACACAGCGACCCAAACCGTGCGCTTGGTTACAGAGCCGACCCTCGATCCGGCGGTGATCTACGGGTATCAAACC $\begin{array}{llllllllllllllllllllllllllllll}\mathrm{L} & \mathrm{Y} & \mathrm{D} & \mathrm{T} & \mathrm{A} & \mathrm{T} & \mathrm{Q} & \mathrm{T} & \mathrm{V} & \mathrm{R} & \mathrm{L} & \mathrm{V} & \mathrm{T} & \mathrm{E} & \mathrm{P} & \mathrm{T} & \mathrm{L} & \mathrm{D} & \mathrm{P} & \mathrm{A} & \mathrm{V} & \mathrm{I} & \mathrm{Y} & \mathrm{G} & \mathrm{Y} & \mathrm{Q} & \mathrm{T}\end{array}$

Fig. 2 (continued on following page). Nucleotide sequence of $i s i A, i s i B$ and flanking regions. The one-letter abbreviations of the deduced amino acid sequences for the products of each gene are shown below the nucleotide sequence; the open reading frames for $i s i A$ and $i s i B$ occupy nucleotide positions 388 to 1413 and 1583 to 2092 respectively. Putative transcriptional stop sites are underlined with inverted arrows. The ' -10 ', -35 ' and ribosome-binding sequences are boxed. The start site of transcription is indicated by a vertical arrow. The potential Fur regulatory sequences are underlined with heavy lines. 


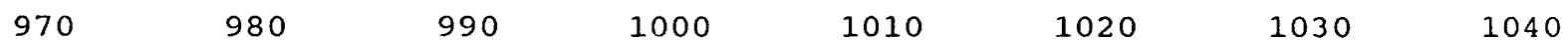
CACTTCGCCACCGTTGATAATCTCGAAGATATCGTTGGTGGCCATATTTATGTGGGTGTACTGCTTGTGGCTGGGGGAAT

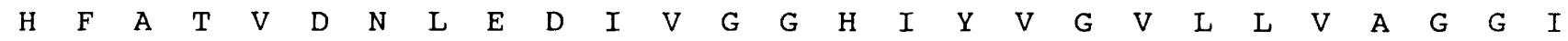
$\begin{array}{lllllll}1050 & 1060 & 1070 & 1080 & 1090 & 1100 & 1110\end{array}$ TTGGCACATTCTCGTGCCGCCACTCCAGTGGGCAAAAAAGGTGCTCCTGTTCTCTGGGGAAGCGATTTTGTCCTATTCCC $\begin{array}{lllllllllllllllllllllllllll}W & H & I & L & V & P & P & L & Q & W & A & K & K & V & L & L & F & S & G & E & A & I & L & S & Y & S\end{array}$

$\begin{array}{lllllll}1130 & 1140 & 1150 & 1160 & 1170 & 1180 & 1190\end{array}$ TGGGGGCGATCGCCTTGGCGGGATTTGTGGCCGCCTACTTCTGCGCAGTGAATACCACGGCCTATCCCGTTGAATTTTAT $\begin{array}{llllllllllllllllllllllllllll}\mathrm{L} & \mathrm{G} & \mathrm{A} & \mathrm{I} & \mathrm{A} & \mathrm{L} & \mathrm{A} & \mathrm{G} & \mathrm{F} & \mathrm{V} & \mathrm{A} & \mathrm{A} & \mathrm{Y} & \mathrm{F} & \mathrm{C} & \mathrm{A} & \mathrm{V} & \mathrm{N} & \mathrm{T} & \mathrm{T} & \mathrm{A} & \mathrm{Y} & \mathrm{P} & \mathrm{V} & \mathrm{E} & \mathrm{F} & \mathrm{Y}\end{array}$ $\begin{array}{lllllll}1210 & 1220 & 1230 & 1240 & 1250 & 1260 & 1270\end{array}$ GGGCCTGTTCTCGATGTCAAACTCAGCATTGTGCCTTACTTTGCCGACACCATCGAGCTCCCCATGAACGAACACACTTC

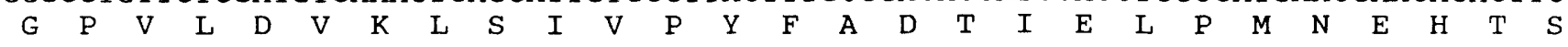
$\begin{array}{lllllll}1290 & 1300 & 1310 & 1320 & 1330 & 1340 & 1350\end{array}$ CCGTGCCTGGTTAGCCAATGCCCATTTCTTCTTTGCCTTTTTCTTCCTCCAGGGGCACCTCTGGCACGCCCTCCGCGCCA $\begin{array}{llllllllllllllllllllllllll}R & A & \text { W } & \text { L } & \text { A } & \text { N } & \text { A } & \text { H } & \text { F } & \text { F } & \text { F } & \text { A } & \text { F } & \text { F } & \text { F } & \text { L } & \text { Q } & \text { G } & \text { H } & \text { L } & \text { W } & \text { H } & \text { A } & \text { L } & \text { R } & \text { A }\end{array}$

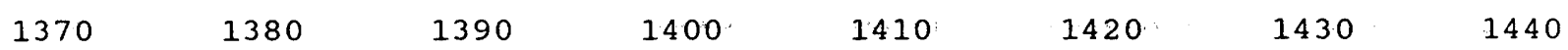
TGGGCTTTGATTTCCGTCGAGTCGAAAAAGTCCTTAGCGATCCACTGGATGCCTAGGTTTTTTAACCGCTACACATCAAC $\begin{array}{llllllllllllllllll}M & G & F & D & F & R & R & V & E & K & V & L & S & D & P & L & D & A\end{array}$ $\begin{array}{lllllll}1450 & 1460 & 1470 & 1480 & 1490 & 1500 & 1510\end{array}$ TTAGTAAAAGTTTTCCTCTCATAGACAATCGGGTTCCATGCAGTGATTTGGAACCTTTTTTCTTPCTCCTAACGCGACTC $\begin{array}{lllllll}1530 & 1540 & 1550 & 1560 & 1570 & 1580 & 1590\end{array}$ TTTTTAGAGTAATTGATTTTTCAATTCAAACAACTTTCTAAAGCAAGATTACGGTTTTAATCATGTCAAAAATTGGTTTA M S K I G L $\begin{array}{lllllll}1610 & 1620 & 1630 & 1640 & 1650 & 1660 & 1670\end{array}$ TTTTTCGGCACACAAACAGGCAACACAGAAGAACTTGCCCAAGCGATCCAAGCGGCCTTTGGTGGTTCAGATATTGTCGA $\begin{array}{lllllllllllllllllllllllllllll}F & F & G & T & Q & T & G & N & T & E & E & L & A & Q & A & I & Q & A & A & F & G & G & S & D & I & V & E\end{array}$ $\begin{array}{lllllll}1690 & 1700 & 1710 & 1720 & 1730 & 1740 & 1750\end{array}$ ACTTTTTGATGTGGCTGAGGTTGATATCGAAGCACTACGGGATTTTGATCAGCTGATCATTGGTTGTCCAACCTGGAATG $\begin{array}{llllllllllllllllllllllllll}\mathrm{L} & \mathrm{F} & \mathrm{D} & \mathrm{V} & \mathrm{A} & \mathrm{E} & \mathrm{V} & \mathrm{D} & \mathrm{I} & \mathrm{E} & \mathrm{A} & \mathrm{L} & \mathrm{R} & \mathrm{D} & \mathrm{F} & \mathrm{D} & \mathrm{Q} & \mathrm{L} & \mathrm{I} & \mathrm{I} & \mathrm{G} & \mathrm{C} & \mathrm{P} & \mathrm{T} & \mathrm{W} & \mathrm{N}\end{array}$ $\begin{array}{lllllll}1770 & 1780 & 1790 & 1800 & 1810 & 1820 & 1830\end{array}$ TGGGAGAACTACAGTCAGACTGGGAAGCCCTCTATGATGATCTCGATGACGTAGACTTTTCAGGAAAAACCATTGCCTAT

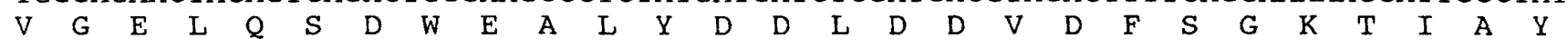
$\begin{array}{lllllll}1850 & 1860 & 1870 & 1880 & 1890 & 1900 & 1910\end{array}$ TTTGGGGCTGGGGATCAAGTGGGCTATGCCGACAATTTTCAGGATGCCATGGGCGTTTTAGAAGAAAAAATTACCAGCCT

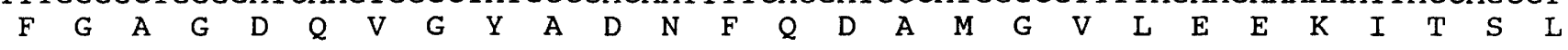
$\begin{array}{lllllll}1930 & 1940 & 1950 & 1960 & 1970 & 1980 & 1990\end{array}$ TGGCGGGAAAACCGTAGGCCAATGGCCCACCGCTGGTTATGACCACAGCGAATCCAAAGCGGAACGGGACGGTAAATTTG $\begin{array}{lllllllllllllllllllllllllll}G & G & K & T & V & G & Q & W & P & T & A & G & Y & D & H & S & E & S & K & A & E & R & D & G & K & F\end{array}$ $20102020 \quad 2030 \quad 2040 \quad 2050 \quad 2060 \quad 2070 \quad 2080$ TCGGTTTGGCGATCGATGAAGATAATCAACCGGAATTGACGGCAGAACGTATTCAAGCTTGGGTTGCCCAACTTAAACCA

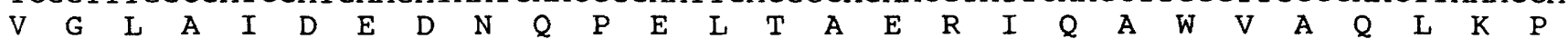

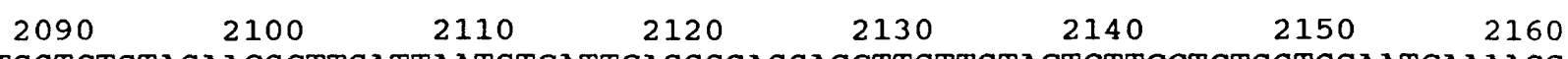
GCCTTTGGTCTGTAGAACGCTTGATTAATGTCATTCAGGGGAGGAGCTTGTTGTACTCTTCCTCTGGTGGAATCAAAAGG A $\quad F \quad G \quad L$

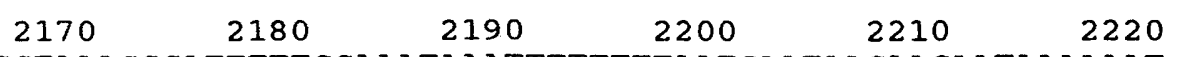
AATTCGGTAAAGGGATTTTTCCAAATAAATTTTTTTTAATCAATAACAACAATAAAAAAT 


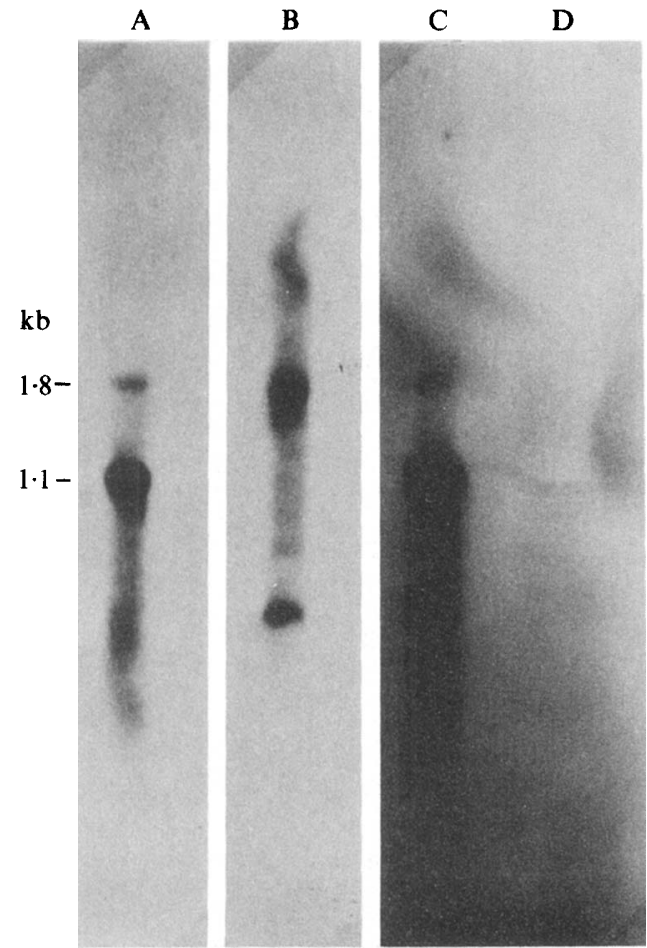

Fig. 3. Transcriptional regulation of the $i s i A B$ operon in response to iron stress. Lanes A, B and C are the Northern blots for RNA from cells under iron stress. The SacI/HindIII fragment (Fig. 1) that was used as the probe for lane A contains sequences from both $i s i A$ and $i s i B$, the $A c c I / C l a I$ fragment that was used as the probe for lane B contains only $i s i B$ sequences, and the $B g I / / S a c I$ fragment that was used as the probe for lane $C$ contains only isiA sequences. Lane $B$ has been exposed much longer than the other lanes to enhance the $1.8 \mathrm{~kb}$ band; this exposure also enhances a lower band that may correspond to the apparent breakdown products of lane A. Lane D is the Northern blot for RNA extracted from cells under the normal iron concentration found in $\mathrm{A}$ medium; the probe for this reaction is the same as in lane $\mathrm{C}$.

9 bases, and has a thermal stability of $\Delta G=-11.0 \mathrm{kcal}$ $\mathrm{mol}^{-1}\left(46 \cdot 0 \mathrm{~kJ} \mathrm{~mol}^{-1}\right)$.

\section{Transcriptional analysis of the isi operon}

To examine how these genes are expressed in Synechococcus PCC 7002, probes containing isiAB (SacI/HindIII, Fig. 1), isiA (BgII/SacI fragments, Fig. 1) and isiB (AccI/ClaI fragment, Fig. 1) were reacted to Northern blots of RNA extracted from cells grown in A medium and in A medium containing $7 \cdot 1 \times 10^{-7} \mathrm{M}$-ferric chloride. No transcripts were detected for cells grown in standard A medium. Under iron-stress conditions the probes containing isiA hybridized to messenger RNA molecules of about $1.8 \mathrm{~kb}$ and $1.1 \mathrm{~kb}$; the probe for isiB only hybridized to the larger messenger molecule (Fig. 3).

Primer extension experiments using a complementary oligonucleotide sequence that is 70 nucleotides downstream from the start codon of isiA indicated a

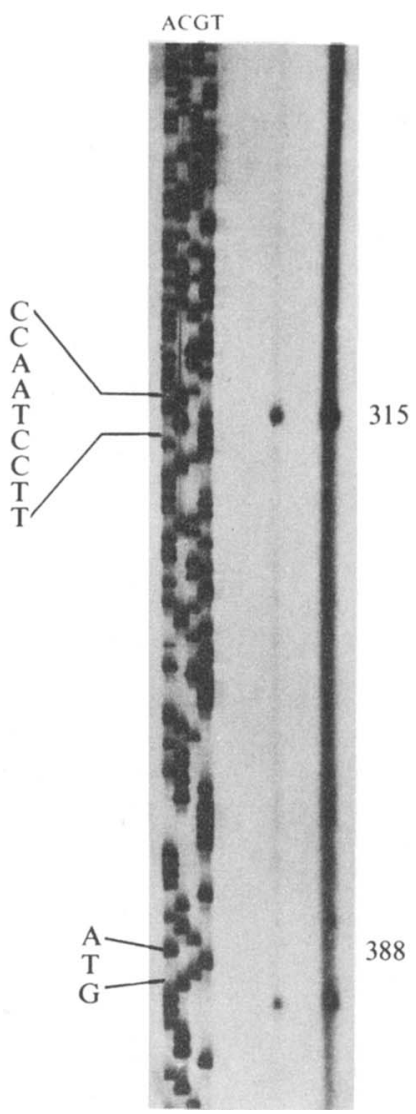

Fig. 4. Primer extension studies to determine the transcriptional start site of the isi $A B$ operon. The sequence ladder was constructed using the same primer that was used in the primer extension reaction. The lanes of the sequencing ladder are labelled with the bases that complement the dideoxynucleotides of each reaction, so that the sequence read from the ladder corresponds to the sequence of Fig. 2. The numbers to the right of the figure correspond to the actual nucleotide position of the sequence in Fig. 2.

transcriptional start site 72 bp upstream of the translation initiation codon for isiA (Fig. 4). This, along with the putative transcription terminators mentioned previously, predicts transcripts of lengths in close agreement (roughly 1185 and 1830 bases) with those estimated from the Northern hybridization analysis.

\section{Cloning, sequencing and transcript analysis of pet $F$ and $p s b C$}

Under iron stress, flavodoxin replaces ferredoxin as the terminal electron acceptor of photosynthesis. Northern blot analysis indicated that the expression of the gene for flavodoxin is regulated at the transcriptional level. To see how the gene for ferredoxin (pet F) is regulated in Synechococcus PCC 7002, a DNA fragment from Synechococcus sp. PCC 7942 containing the gene for ferredoxin was used to clone this gene from Synechococcus sp. PCC 7002 as a $1.6 \mathrm{~kb}$ HindIII fragment in 


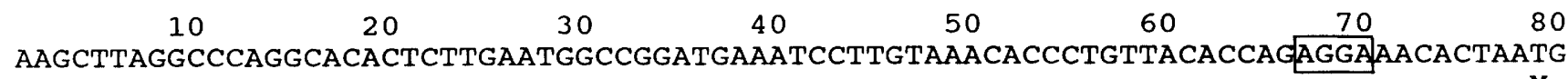

$\begin{array}{lllllll}90 & 100 & 110 & 120 & 130 & 140 & 150\end{array}$
GCTACATATAAGGTTACACTCATCACTCCCGACGGCGAAGTATCCTACGACGCTCCCGATGATGAATACATTCTAGACTC

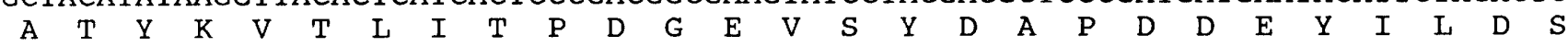
$\begin{array}{lllllll}170 & 180 & 190 & 200 & 210 & 220 & 230\end{array}$ CGCCGGTGATGCTGGTTATGACCTTCCTGCATCCTGCCGTGCCGGTGCTTGCTCCACCTGTGCTGGTAAGATCGTTTCCG $\begin{array}{llllllllllllllllllllllllll}A & G & D & A & G & Y & D & \text { L } & \text { P } & \text { A } & \text { S } & \text { C } & \text { R } & \text { A } & G & \text { A } & \text { C } & \text { S } & \text { T } & \text { C } & \text { A } & G & K & I & V & S\end{array}$ $\begin{array}{lllllll}250 & 260 & 270 & 280 & 290 & 300 & 310\end{array}$ GTACTGTTGACCAATCCGAACAGTCCTTCCTCGATGATGATCAAATTGAAGCGGGTTACGTTCTGACCTGTATTGCTTAT $\begin{array}{lllllllllllllllllllllllllllll}G & T & V & D & Q & S & E & Q & S & F & L & D & D & D & Q & I & E & A & G & Y & V & L & T & C & I & A & Y\end{array}$

$\begin{array}{lllllll}330 & 340 & 350 & 360 & 370 & 380 & 390\end{array}$
CCTCAATCTGATGTCACCATCGAAACTAACAAAGAGGAAGAACTCTACTAGAATTTCTCGGCCCACCCTTGGCAACTAGA $\begin{array}{llllllllllllllll}P & Q & S & D & V & T & I & E & T & N & K & E & E & E & L & Y\end{array}$

410

420

430

440

450

460

470

480

TAAATAGAACATTTAGAAGTGTTTCCCTTGGGAAGCGCTTCTATTTTTTTGCGCCACGGGGTGCAAGTACAAAAAAATCC

Fig. 5. Nucleotide sequence of petF and its flanking regions. The one-letter abbreviations for the deduced amino acid sequence are shown below the nucleotide sequence. The putative transcriptional stop site is underlined with inverted arrows. The potential ribosomebinding site is boxed.

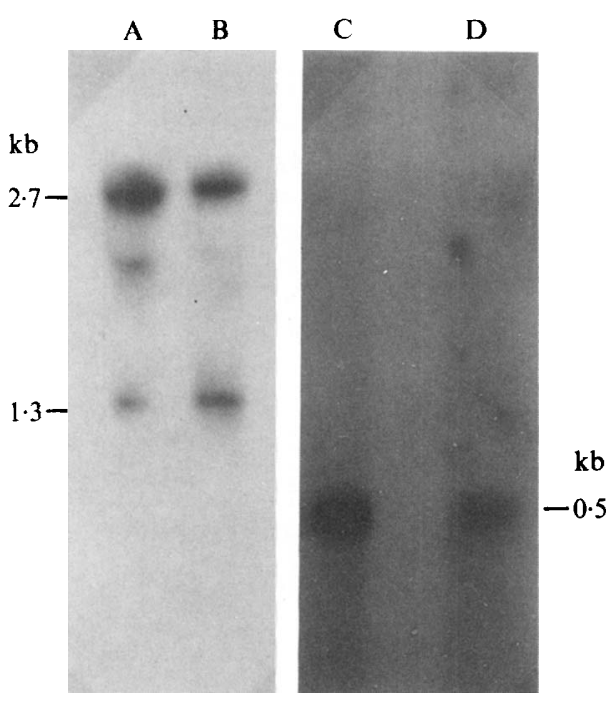

Fig. 6. Transcript analysis of the genes for ferredoxin and CP-43 in normal and iron-stressed cells. Lanes A and B represent Northern blots for RNA from normal and iron-stressed cells respectively. These were probed with a $3 \mathrm{~kb}$ HindIII fragment containing all of $p s b D I$ and the first half of $p s b C$. The $2.7 \mathrm{~kb}$ transcript contains the messages from the dicistronic $p s b D I-p s b C$ operon, while the $1.3 \mathrm{~kb}$ transcript is the message from $p s b D I I$. Lanes $\mathrm{C}$ and D represent Northern blots for RNA from normal and iron-stressed cells, respectively, probed with a $1.6 \mathrm{~kb}$ HindIII fragment containing all of the gene for ferredoxin I (petF).

M13mp19. Sequencing of this fragment revealed a $291 \mathrm{bp}$ open reading frame corresponding to a mature polypeptide of 96 amino acids (assuming proteolytic cleavage of the first methionine; Matsubara et al., 1978).
Fig. 5 contains the sequence of the pet $F$ gene of Synechococcus sp. PCC 7002. The decoded protein sequence shares a similarity of $75 \%$ with ferredoxin I of Anabaena sp. PCC 7120 (Alam et al., 1986) and of $73 \%$ with that of Synechococcus sp. PCC 7942 (Reith et al., 1986). A potential transcriptional terminator is found 42 bases after the stop codon. It consists of a 12-base stem and a loop of 2 bases followed by 6 Ts with a predicted thermal stability of $\Delta G=-13.0 \mathrm{kcal} \mathrm{mol}^{-1}(54.4 \mathrm{~kJ}$ $\mathrm{mol}^{-1}$ ). A potential ribosome-binding site (AGGA) was found 7 bases upstream of the initiation codon.

Northern blot analysis of RNA from cells grown in normal $\mathrm{A}$ medium or in $\mathrm{A}$ medium containing $7 \cdot 1 \times 10^{-7} \mathrm{M} \mathrm{FeCl}_{3}$ indicated that pet $F$ is transcribed in both iron-replete and iron-stress conditions (Fig. 6, lanes $\mathrm{C}$ and $\mathrm{D})$. The cloned probe of pet $F$ reacted to a message of about 570 bases, indicating that pet $F$ is located in a monocistronic operon.

The sequence for psbC of Synechococcus sp. PCC 7002 can be found in Gingrich et al. (1990). This gene was also cloned and sequenced in our laboratory. The sequence generated from these clones was identical to that reported by Gingrich et al. (1990).

Northern hybridization experiments using RNA from cells grown in $\mathrm{A}$ medium and in $\mathrm{A}$ medium containing $7 \cdot 1 \times 10^{-7} \mathrm{M} \mathrm{FeCl}_{3}$ indicated that $p s b C$ is transcribed in both the iron-replete and the iron-stressed conditions of these experiments (Fig. 6, lanes A and B). The transcript length was $2.7 \mathrm{~kb}$, which is long enough to encode both $p s b D I$ and $p s b C$, and is in agreement with the results of Gingrich et al. (1990). 


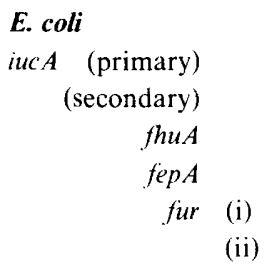

Synechococcus sp. PCC 7942

isiAB (i) AAC TTATTGAGAATTATT GTA

(ii) ACT TAATATCAACTTATT GAG

(iii) TCT TTATTGAGAGTAATT TCT

irpA TGA TTATTATT CTCATT TTT

Synechococcus sp. PCC 7002

$\begin{array}{rllll}\text { isiAB } & (+5) & \text { CCT } & \text { TTATTGCCAAATATA } & \text { TGC } \\ & (-29) & \text { ACT } & \text { TTACTGAGAATAATT } & \text { GTA } \\ & (-183) & \text { TTC } & \text { ATATCAAAACTGATT } & \text { AGC } \\ & (-229) & \text { TGA } & \text { TAATTAATAGTGATA } & \text { AAA }\end{array}$

Fig. 7. Comparison of inferred Fur regulatory sequences with the Fur-binding site in the aerobactin promoter. The Fur-binding sequences of the iuc $A$ promoter have been used to line up published sequences with inferred iron regulatory functions. The Synechococcus sp. PCC 7002 sequences have been selected as those sequences best fitting the nucleotides that are invariant $\left({ }^{*}\right)$ in the published $E$. coli iron-regulated promoters (de Lorenzo et al., 1987).

\section{Discussion}

When cyanobacteria are exposed to iron stress, a dramatic decrease in phycocyanin occurs, the chlorophyll content and organization within the thylakoid membrane changes, and flavodoxin replaces ferredoxin as the terminal electron acceptor of photosystem I (Hutber et al., 1977; Guikema \& Sherman, 1983; Sandmann, 1985; Riethman \& Sherman, 1988b; Pardo et al., 1990). In iron-stressed Synechococcus sp. PCC 7942 a new photosystem II chlorophyll-binding complex CPVI-4 appears that contains an iron-stress-induced 36 $\mathrm{kDa}$ chlorophyll-binding protein (Riethman \& Sherman, $1988 a, b)$.

In Synechococcus sp. PCC 7942 the ferredoxin gene, pet $F$, is transcribed into a monocistronic message that is constitutively expressed under all iron regimes; thus, ferredoxin expression appears to be regulated in a posttranscriptional manner (Reith et al., 1986; Laudenbach et al., 1988). The appearance of flavodoxin, however, is tightly regulated at the transcriptional level (Laudenbach et al., 1988). The flavodoxin message, which is not detectable in iron-replete conditions, appears under ironstress conditions and rapidly disappears when iron is added back to the medium. In Synechococcus sp. PCC 7942 flavodoxin is the second open reading frame of an iron-stress-induced operon (isi $A B$ ) which yields two messages when transcribed. The larger message contains both $i s i A$ and $i s i B$; the smaller message contains only isi $A$ and is about nine times more abundant than the dicistronic message (Laudenbach et al., 1988). The putative protein deduced from the sequence of isiA is very similar to CP-43 (Laudenbach \& Straus, 1988).

We have studied the organization and expression of the genes for flavodoxin, ferredoxin and CP-43 in the marine cyanobacterium Synechococcus sp. strain PCC 7002. We found that, as in Synechococcus sp. PCC 7942, the gene for ferredoxin is constitutively transcribed in both iron-replete and iron-stress conditions. We also showed that $p s b C$ is constitutively expressed under ironstress and iron-sufficient conditions. The gene for flavodoxin is part of an iron-stress-regulated dicistronic operon with similar arrangement and pattern of expression to that of the freshwater Synechococcus sp. PCC 7942. The first gene of this operon (isiA) is similar to $p s b C$ and under iron-stress conditions is found on a dicistronic message of about 1800 nucleotides and a more abundant message of 1100 nucleotides. As in Synechococcus sp. PCC 7942, isi $A$ and $i s i B$ are separated by a palindromic structure; however, unlike Synechococcus sp. PCC 7942, which contained no obvious termination structure downstream from the flavodoxin gene, Synechococcus sp. PCC 7002 has a potential transcriptional termination signal 19 nucleotides downstream of $i s i B$.

\section{Regulatory sequences upstream of the isiAB operon}

Primer extension analysis indicated a 72-base leader sequence for the isi transcripts of Synechococcus sp. PCC 7002. Based on this, other potential regulatory sequences have been identified (Fig. 2). A GATAAA sequence in the -10 region bears similarity to the consensus $E$. coli promoter -10 region sequence and the TTGAAC sequence in the -35 region is similar to the $E$. coli consensus of TTGACA (Rosenberg \& Court, 1979).

In $E$. coli the Fur repressor binds to the fur regulatory sequences in the aerobactin promoter to repress transcription during iron-replete conditions (de Lorenzo et al., 1987). Similar sequences are found in the promoter regions of other $E$. coli iron-regulated genes: fur, fhuA, 
and fepA (Bagg \& Neilands, 1987; de Lorenzo et al., 1987). In Synechococcus sp. PCC 7942 there are three 17base sequences, approximately 15,25 , and $150 \mathrm{bp}$ upstream of the transcription start site of the isiAB message, which resemble the Fur-binding sequence of the aerobactin promoter (de Lorenzo et al., 1987; Laudenbach \& Straus, 1988). Synechococcus sp. PCC 7942 also contains fur consensus sequences upstream to $\operatorname{irp} A$, which is thought to transcribe a product involved in the acquisition or storage of iron (Reddy et al., 1988). In Synechococcus sp. PCC 7002, potential fur consensus sequences have been located 5 nucleotides downstream, and 29, 183 and 229 nucleotides upstream from the transcriptional start site. Fig. 7 compares the identified fur consensus sequences of Synechococcus sp. PCC 7002 to those that were identified for the aerobactin promoter and those that have been inferred for other ironregulated genes.

\section{The putative protein product of isiA}

In Synechococcus sp. PCC 7002, the isiA gene encodes a putative polypeptide (IsiA) of 342 amino acids that is $40 \%$ similar to the amino acid sequence deduced for CP-43 (Gingrich et al., 1990). The most striking difference between CP-43 and IsiA is a deletion of about 120 largely hydrophilic amino acids between the last two hydrophobic domains of CP-43. Thus, the similarity between CP-43 and IsiA is enhanced to $48 \%$ when only the first 286 amino acids are compared. Characteristics shared with other chlorophyll-binding polypeptides reported for the isiA gene product of Synechococcus sp. PCC 7942 (Laudenbach \& Straus, 1988) hold true for that of Synechococcus sp. PCC 7002. The $p s b B$ (CP-47) and psbC (CP-43) (Alt et al., 1984), and the isi $A$ gene products possess seven major hydrophobic regions, at least some of which could form membrane-spanning helices. In photosynthetic bacteria, histidine residues are believed to play an important role by binding bacteriochlorophyll via the $\mathrm{Mg}$ atom in pigment-protein complexes (Zuber, 1986). In CP-47 of Synechococcus sp. PCC 6803, histidine residues separated by 13 or 14 amino acids are located in five of the putative membrane-spanning regions (Vermaas et al., 1987). The same spacing of histidine residues has also been found in chlorophyll-protein complexes of PSI (Fish et al., 1985). Five sets of histidines separated by 13 or 14 amino acids, three of which occur within putative membrane-spanning segments reported for the Synechococcus sp. PCC 7942 isiA gene product, are conserved in Synechococcus sp. PCC 7002. The chlorophyll-binding sequence Ala-X-X-X-His (Youvan \& Ismail, 1985) is also found in residues 124 to 128 of the isiA gene product of Synechococcus sp. PCC 7002.

Pakrasi et al. (1985) identified an iron-stress-induced photosystem II chlorophyll-protein complex that contained a chlorophyll $a$ binding protein with a molecular mass of $36 \mathrm{kDa}$. This polypeptide formed the major chlorophyll--protein complex in Synechococcus sp. PCC 7942 cells grown in media not containing iron. These authors postulated that this $36 \mathrm{kDa}$ polypeptide forms part of an intermediate light-harvesting antenna for photosystem II that acts as a replacement for phycobilisomes during iron depletion. Interestingly, the proposed function of CP-43 is also that of interior chlorophyll $a$ light-harvesting antennae for PSII (Bricker, 1990; Vermaas \& Ikeuchi, 1991). Riethman \& Sherman $(1988 a, b)$ suggested that this protein may also act as a chlorophyll $a$ reservoir and be involved with membrane development during recovery from iron stress.

Since isiA is induced by iron-stress conditions, it is reasonable to assume that its $\mathrm{CP}-43$-like product might compensate in some way for the lack of available iron. Iron is associated with photosystem II as the nonhaem iron bound between QA and QB, and in the haems of cytochrome $b 559$. Whether the product of isiA replaces a photosystem II protein (CP-43 for example) under iron stress in a way that compensates for the lack of iron, or acts as a reservoir for chlorophyll as suggested by Riethman \& Sherman $(1988 a, b)$, has yet to be determined.

We would like to acknowledge the excellent technical assistance of Bess Wong. We would also like to thank S. Golden for providing the Synechococcus sp. PCC 7942 psbC probe. This work was supported by a grant from the Natural Sciences and Engineering Council of Canada.

\section{References}

Alam, J., Whitaker, R. A., Krogmann, D. W. \& Curtis, S. E. (1986). Isolation and sequence of the gene for ferredoxin I from the cyanobacterium Anabaena sp. PCC 7120. Journal of Bacteriology 168, $1265-1271$.

Alt, J., Morris, J., Westoff, P. \& HerrmanN, R. G. (1984). Nucleotide sequence of the clustered genes for the $44 \mathrm{kd}$ chlorophyll $a$ apoprotein and the " $3 \mathrm{kd}$ "-like protein of the Photosystem II reaction center in the spinach plastid chromosome. Current Genetics 8, 597606.

BagG, A. \& NeIlands, J. B. (1987). Molecular mechanism of regulation of siderophore-mediated iron assimilation. Microbiological Reviews 51, 509-518.

Boyer, G. L., Gillam, A. H. \& Trick, C. (1987). Iron chelation and uptake. In The Cyanobacteria, pp. 415-436. Edited by P. Fay \& C. Van Baalen. Amsterdam, New York \& Oxford: Elsevier.

BRICKER, T. M. (1990). The structure and function of CPa-1 and CPa-2 in Photosystem II. Photosynthesis Research 24, 1-13.

CrosA, J. H. (1989). Genetics and molecular biology of siderophoremediated iron transport in bacteria. Microbiological Reviews 53, 517530.

Dale, R. M. K., McClure, B. A. \& Houchins, J. P. (1985). A rapid single-stranded cloning strategy for producing a sequential series of overlapping clones for use in DNA sequencing. Application to sequencing the corn mitochondrial 18S rRNA. Plasmid 13, 31-40.

DRUMmond, M. H. (1985). The base sequence of the nifF gene of Klebsiella pneumoniae and homology of the predicted amino acid sequence of its protein product to other flavodoxins. Biochemical Journal 232, 891-896. 
FISH, L. E., KUCK, U. \& BOGORAD, L. (1985). Two partially homologous adjacent light-inducible maize chloroplast genes encoding polypeptides of the $\mathrm{P} 700$ chlorophyll $a$ protein complex of photosystem I. Journal of Biological Chemistry 260, 1413-1421.

Gendel, S., Straus, N. A., Pulleyblank, D. \& Williams, J. (1983). A novel shuttle cloning vector for the cyanobacterium Anacystis nidulans. FEMS Microbiology Letters 19, 291-294.

Gingrich, J. C., Gasparich, G. E., Sauer, K. \& Bryant, D. A. (1990). Nucleotide sequence and expression of the two genes encoding D2 protein and the single gene encoding the CP43 protein of photosystem II in the cyanobacterium Synechococcus sp. PCC 7002. Photosynthesis Research 24, 137-150.

Golden, S. S., Brusslan, J. \& Haselkorn, R. (1987). Genetic engineering of the cyanobacterial chromosome. Methods in Enzymo$\log y 153,215-231$.

Guikema, J. A. \& Sherman, L. A. (1983) Organization and function of chlorophyll in membranes of cyanobacteria during iron starvation. Plant Physiology 73, 250-256.

HANAHAN, D. (1985). Techniques for transformation of E. coli. In DNA Cloning : a Practical Approach, vol. 1, pp. 109-135. Edited by D. M. Glover. Oxford: IRL Press.

Hutber, G. N., Hutson, K. G. \& Rogers L. J. (1977). Effect of iron deficiency on levels of two ferredoxins and flavodoxin in a cyanobacterium. FEMS Microbiology Letters 1, 193-196.

KJEMS, J. \& GARRETT, R. A. (1988). Novel splicing mechanism for the ribosomal RNA intron in the archaebacterium Desulfurococcus mobilis. Cell 54, 693-703.

Laudenbach, D. E. \& Straus, N. A. (1988). Characterization of a cyanobacterial iron stress-induced gene similar to psbC. Journal of Bacteriology 170, 5018-5026.

Laudenbach, D. E., Reith, M. E. \& Straus, N. A. (1988). Isolation, sequence analysis, and transcriptional studies of the flavodoxin gene from Anacystis nidulans R2. Journal of Bacteriology 170, 258-264.

Leonhardt, K, G. \& Straus, N. A. (1989). Sequence of flavodoxin from Anabaena variabilis 7120. Nucleic Acids Research 17, 4384

de Lorenzo, V., WeE, S., Herrero, M. \& Neilands, J. B. (1987). Operator sequences of the aerobactin operon of plasmid ColV-K 30 binding the ferric uptake regulation (fur) repressor. Journal of Bacteriology 169, 2624-2630.

Matsubara, H., Hase, T., Wakabayashi, S. \& Wada, K. (1978). Gene duplications during evolution of chloroplast-type ferredoxins. In The Evolution of Protein Molecules, pp. 209-219. Edited by H. Matsubara \& T. Yamada. Tokyo: Japan Scientific Societies Press.

Milligan, B. G. (1989). Purification of chloroplast DNA using hexadecyltrimethylammonium bromide. Plant Molecular Biology Reporter 7, 144-149.

Pakrasi, H. B., Riethman, H. C. \& Sherman, L. A. (1985). Organization of pigment proteins in the photosystem II complex of the cyanobacterium Anacystis nidulans R2. Proceedings of the National Academy of Sciences of the United States of America 82 , 6903-6907.

Pardo, M. B., Gomez-Moreno, C. \& Peleato, M. L. (1990). Effect of iron deficiency on ferredoxin levels in Anabaena variabilis PCC 6309. Archives of Microbiology 153, 528-530.

PIRrotTA, V. (1986). Cloning Drosophila genes. In Drosophila: a Practical Approach, pp. 83-110. Edited by D. B. Roberts. Oxford: IRL Press.

Reddy, K. J., Bullerjahn, G. S., Sherman, D. M. \& Sherman, L. A. (1988). Cloning, nucleotide sequence, and mutagenesis of a gene (irpA) involved in iron-deficient growth of the cyanobacterium Synechococcus sp. strain PCC7942. Journal of Bacteriology 170, 44664476.

Reith, M. E., Laudenbach, D. E. \& Straus, N. A. (1986). Isolation and nucleotide sequence analysis of the ferredoxin I gene from the cyanobacterium Anacystis nidulans R2. Journal of Bacteriology 168, $1319-1324$.

Riethman, H. C. \& Sherman, L. A. (1988a). Immunological characterization of iron-regulated membrane proteins in the cyanobacterium Anacystis nidulans R2. Plant Physiology 88, 497-505.

Riethman, H. C. \& Sherman, L. A. (1988b). Purification and characterization of an iron stress-induced chlorophyll-protein from the cyanobacterium Anacystis nidulans R2. Biochimica et Biophysica Acta 935, 141-151.

ROSENBERG, M. \& CoURT, D. (1979). Regulatory sequences involved in the promotion and termination of RNA transcription. Annual Review of Genetics 13, 319-353.

Sambrook, J., Fritsch, E. F. \& Maniatis, T. (1989). Molecular Cloning: a Laboratory Manual, 2nd end. Cold Spring Harbor, NY: Cold Spring Harbor Laboratory.

SandmanN, G. (1985). Consequences of iron deficiency on photosynthetic electron transport in blue green algae. Photosynthesis Research 6, 261-271

Smith, W. W., Pattridge, K. A., Ludwig, M. L., Petsko, G. A., Tsernoglou, D., TANaKa, N. \& Yasunobu, K. T. (1983). Structure of oxidized flavodoxin from Anacystis nidulans. Journal of Molecular Biology 165, 737-755.

Stevens, S. E., JR \& Porter, R. D. (1980). Transformation in Agmenellum quadruplicatum. Proceedings of the National Academy of Sciences of the United States of America 77, 6052-6056.

VermaAs, W. F. J. \& IkeUchi, M. (1991). Photosystem II. In The Photosynthetic Apparatus: Molecular Biology and Operation, pp. 25111. Edited by L. Bogorad \& I. K. Vasil. San Diego: Academic Press.

Vermaas, W. F. J., Williams, J. G. K. \& ARntzen, C. J. (1987). Sequencing and modification of $p s b B$, the gene encoding the CP-47 protein of photosystem II, in the cyanobacterium Synechocystis 6803 . Plant Molecular Biology 8, 317-326.

Youvan, D. C. \& IsMaIL, S. (1985). Light-harvesting II (B800-850 complex) structural genes from Rhodopseudomonas capsulata sp. Proceedings of the National Academy of Sciences of the United States of America 82, 58-62.

ZUBER, H. (1986). Structure of light-harvesting antenna complexes of photosynthetic bacteria, cyanobacteria and red algae. Trends in Biochemical Sciences 11, 414-419. 